\title{
A study to estimate prevalence and risk factors of Obstructive Sleep Apnea Syndrome in a semi-urban Indian population
}

\author{
Abhijeet Singh, Rajendra Prasad, Rajiv Garg, Surya Kant, Giridhar B. Hosmane, \\ Abhisek Dubey, Abhisek Agarwal, Ram Kishun Verma \\ Department of Pulmonary Medicine, King George Medical University, Lucknow, Uttar Pradesh, India
}

\begin{abstract}
Obstructive Sleep Apnea Syndrome (OSAS) has been recognised as a major cause of morbidity and mortality in developing countries like India. There is still a paucity of Indian studies regarding the prevalence of
\end{abstract}

Corresponding author: Dr. Rajendra Prasad, MD, FAMS, FCCP (USA), FNCCP, D.Sc Professor and Head, Department of Pulmonary Medicine, King George Medical University, Lucknow- 226003, India.

E-mail ID: rprasaddirvpci@gmail.com

Key words: Obstructive Sleep apnea; Berlin questionnaire; Epworth sleepiness scale score (ESS Score); obesity; hypertension.

Conflict of interest: the authors declare no conflict of interest.

Acknowledgement: We thankfully acknowledge the staff members of the polysomnography laboratory (Mr Vijay Kumar Verma and Mr Vivek Tiwari) for performing polysomnography and collecting reliable and meaningful information about our study subjects.

Authors' contributions: AS, RP, RG, SK, contributed in the form of valuable intellectual inputs in the diagnosis and management of cases and analysis of data; $\mathrm{GBH}, \mathrm{AA}, \mathrm{AD}, \mathrm{RKV}$, have worked for the cases including data recording.

Research Highlights:

- Obstructive Sleep Apnea Syndrome (OSAS) has been recognised as a major cause of morbidity and mortality in recent years.

- It still remains largely unrecognised and undiagnosed in developing countries like India.

- There is a paucity of literature on prevalence and risk factors of OSAS in adults from various regions of India as current information is insufficient.

- The high sensitivity of Berlin Questionnaire in this study has made an impression that it still can be used as a pre-assessment tool for predicting persons at risk for OSAS in clinical practice as performing polysomnography on every subject is labour intensive.

- OSAS is a common disease and there is high demand for its awareness, evaluation, diagnosis and management among primary care physicians.

Received for publication: 13 September 2016

Accepted for publication: 10 March 2017

(C) Copyright A. Singh et al., 2017

Tipografia PI-ME Editrice, Italy

Monaldi Archives for Chest Disease 2017; 87:773

doi: 10.4081/monaldi.2017.773

This article is distributed under the terms of the Creative Commons Attribution Noncommercial License (by-nc 4.0) which permits any noncommercial use, distribution, and reproduction in any medium provided the original author(s) and source are credited.
OSAS. The current single centre prospective cross-sectional study was undertaken to know prevalence estimates for key symptoms and features that can indicate the presence of OSAS in an Indian population. A survey was conducted on subjects with age groups $\geq 25$ years at King George's Medical University, Lucknow, Uttar Pradesh, India from August 2009 to July 2011. Data was recorded during the interview on the basis of Berlin Questionnaire (BQ). Risk factors for OSAS were also evaluated. Risk group categorization for OSAS was done with the help of a questionnaire and overnight polysomnography was performed in each group to measure apnea and hypopnea index (AHI). Out of 1816 subjects, 1512 (response rate $83.3 \%$ ) finally participated in the survey with mean age $42.6 \pm 11.2$ years, males $67.9 \%$ and females $32.1 \%$. Of them $6.2 \%$ were found to be at high-risk OSAS; $12.2 \%$ were obese (Body Mass Index $\geq 30$ $\mathrm{kg} / \mathrm{m}^{2}$ ) and $33.5 \%$ of the obese population were at high-risk OSAS. Among high-risk patients with OSAS, $62.4 \%$ had hypertension. Statistically significant and independent risk factors found for OSAS were obesity, large neck size, alcoholism and use of sedatives/tranquillizers. Highrisk category predicted an $\mathrm{AHI} \geq 5$ with a sensitivity of $86.3 \%(95 \% \mathrm{CI}$ 73.1-93.8), specificity of $93.1 \%$ (95\% CI 89.1-95.7), positive and negative predictive values of $70.9 \%$ (95\% CI 57.9-81.4) and $97.2 \%$ (95\% CI 94.198.8) respectively. It can be concluded that $\mathrm{BQ}$ questionnaire can still be used as a pre-assessment tool for predicting persons at risk for OSAS in clinical practice. Further studies on estimation of prevalence of OSAS by applying BQ are warranted in near future from other regions of India.

\section{Introduction}

Obstructive sleep apnea syndrome (OSAS) is a disorder of breathing during sleep characterized by prolonged partial upper airway obstruction or intermittent complete obstruction that disrupts normal sleep patterns and are often associated with arousals, sleep fragmentation, intermittent hypoxia and hypercapnia along with serious neurobehavioral and cardio-respiratory consequences, including excessive daytime sleepiness (EDS), growth failure, school failure, behavioral problems or cor-pulmonale, automobile accidents or even sudden death. OSAS has long been recognised as a major contributor to morbidity and mortality in developed countries. The prevalence of OSAS based on the Wisconsin cohort study performed in the USA involving middle-aged adults 30-60 year of age, is $2 \%$ in females and $4 \%$ in males [1]. The public health impact of OSAS is now enormous in developing countries like India because of increasing urbanisation as well as lifestyle modification and its potential contribution to the increased rates of cardiovascular disease and obesity. A study has estimated OSAS prevalence of 3.6\% in an Indian community based sample translating to over 36 million affected individuals as when extrapolated to the overall population of over one billion in India that carries a substantive public heath significance [2]. Overnight supervised in-laboratory polysomnography (PSG) is recommended for establishing the diagnosis and further prioritizing management strate- 
gies. However, these studies are time-consuming, expensive and labour intensive. The occurrence of first night effect leads to subjective discomfort making it more impracticable. Therefore, it is rarely feasible to use PSG as a screening test in large-scale epidemiological studies. Unattended portable home PSG using portable digital recorders is an emerging and reliable alternative in resource-limited settings. It can overcome many disadvantages of former but still has limitations such as inferior data quality due to lack of supervision and electroencephalography (EEG) leads and variable scoring schemes as well as sensor devices. This could lead to increase false positive and negative cases. Therefore, clinical assessment is necessary for validation of findings with portable PSG. It would be useful to rely on a screening test that could reliably identify either high-risk patients requiring full PSG or low-risk patients in whom PSG could be avoided among densely populated countries. Therefore, the development of screening or casefinding instruments such as Berlin Questionnaire (BQ) is imperative to identify and treat OSAS. Despite deliberate efforts made by researchers in India with resource-limited settings in the last decade, OSAS still remains largely unrecognised and undiagnosed [2-6]. The primary care physicians are still unaware of OSAS. The current study was conducted to know the prevalence estimates of key symptoms and features that can indicate the presence of OSAS in an Indian semi-urban population.

\section{Materials and Methods}

A single-center prospective, cross-sectional study was conducted on consecutive and apparently healthy attendants with no complaints, who were attending the of Kasturba Chest Hospital, Department of Pulmonary Medicine, King George's Medical University (KGMU), Lucknow, Uttar Pradesh, India. The attendants were interviewed face to face using pretested BQ on three days of every week (Monday, Tuesday and Wednesday) from August 2009 to July 2011. The apparently healthy attendants with age $\geq 25$ years were recruited in this study. These subjects were coming along with patients referred to outdoor of this tertiary care referral centre from all districts of Uttar Pradesh which is the highest populated state carrying almost one-fourth burden of entire population of India. The BQ as a screening tool was developed in 1996 and its origin and use in primary care has been reported previously [7]. This contains a set of known symptoms and clinical feature associated with OSAS. One introductory question and four follow-up questions concerned snoring, witnessed apneas and the frequency of such events. Three questions addressed EDS with a sub-question about drowsy driving. One question was asked for a history of hypertension. Body mass index (BMI) in $\mathrm{kg} / \mathrm{m}^{2}$ was calculated from height and weight recorded on proforma. Bilingual physicians translated the questionnaire from its original English version into Hindi. Translation was performed from Hindi back into English by other bilingual physician and was consistent with the intent of the original version. Criteria for exclusion were patients having age $<25$ years, co-existing systemic diseases like connective tissue disorder, chronic liver disease, chronic renal disease, chronic lung diseases, immunosuppressive disease, malignancies and some heart diseases (except hypertension or vascular morbidity), moribund state and pregnant as well as lactating females. The patients directly reporting with symptoms of OSAS were also excluded in order to avoid selection bias. The study population ready to participate and co-operate in the study with the help of informed consent, were enrolled and their data was recorded on a pre-designed proforma. The subjects were interviewed on the basis of $\mathrm{BQ}$ to elicit information from the subjects themselves and from their partners about the occurrence of snoring, cessation of breathing during sleep, tiredness, sleepiness while driving or any past history of hypertension. Some of the subjects along with their partners were interviewed on telephone in order to get appropriate information regarding snoring habits. The EDS was also assessed by Epworth sleepiness scale (ESS) [8]. Questions were also asked to evaluate possible risk factors for OSAS like smoking, alcoholism and use of sedatives or tranquilizers. Categorization of the subjects in two groups (high-risk and low-risk) was done with the help of questionnaire. Risk grouping for high-risk and low-risk for OSAS was based on responses grouped into three categories. In category 1 , a positive score for high-risk was defined as frequent symptoms (i.e., "more than three to four times per week or almost every day") in two or more questions about snoring and witnessed apneas. In category 2 , a positive score for high-risk was frequent symptoms in two or more questions about awakening sleepy or tiredness after sleeping, wake time sleepiness and/or drowsy driving. In category 3 , a positive score for high-risk was defined as presence of hypertension and/or obesity (BMI $30 \mathrm{~kg} / \mathrm{m}^{2}$ ). To score "high-risk" for OSAS, an individual's questionnaire should have had positive scores in two of the three categories, or in all three. Those patients who denied having symptoms with such frequency or who qualified in only one category were placed into a lower risk group. Neck size (in inches) was measured at the level of cricoid cartilage. Blood pressure measurement (in $\mathrm{mm}$ of $\mathrm{Hg}$ ) was recorded in sitting and standing position after at least ten minutes of rest according to Joint National Committee (JNC)-7 criteria [9]. Another recording was done further after ten minutes along with any previous history of any anti-hypertensive medication in case of first recording was found to be abnormal. This was done in order to reduce the probability of false risk group categorization. Obesity was defined by calculation of body mass index according to classification $\left(30 \mathrm{~kg} / \mathrm{m}^{2}\right)$ recommended by World Health Organization (WHO) [10]. All the subjects from high-risk OSAS category were invited for PSG. However, only $20 \%$ of the subjects from lowrisk OSAS category (selected using a computer-generated random number list) were invited for PSG due to operational as well as financial constraints in order to achieve wide variance in the expected Apnea and Hypopnea index (AHI) scores. AHI is the sum of the total number of obstructive apnea and the total number of hypopneas divided by total sleep time in hours. All consented subjects underwent overnight PSG within one week of screening by estimation of AHI scores. These subjects were also examined for upper airway anomalies such as macroglossia, pharyngeal crowding, bulky uvula, retrognathia, tonsillar enlargement and deviated nasal septum by a specialist otorhinolaryngologist. Further routine checkup was done including complete blood count, liver and renal function test, lipid profile, thyroid function test, fasting and post-prandial blood sugar as well as spirometry. Blood pressure was recorded before and after the sleep study. All subjects underwent PSG within seven days of completing the questionnaire with proper instructions such as avoidance of alcohol anxiolytic/ sedative drugs/ caffeine intake and also not to sleep in the afternoon. Subjects were attached to S-7000 computerized polysomnography machine (manufactured by Cogent Technologies in UK for Embla System Inc.) with 20 channel inputs by standard gold cups after cleansing the area of attachment by spirit followed by application of Nuprep. Subject was requested to sleep at around 10:00 p.m. Various parameters were observed including Electroencephalogram (EEG), Electrooculogram (EOG), Electrocardiogram (ECG), Chin and leg electromyogram (EMG), nasal airflow, thoracoabdominal movements and body position. PSG was recorded for at least 6 hours. Sleep data recorded by the computer was cross-checked manually for scoring of sleep stages, apneas and hypopneas regarding each subject. Apnea was defined as cessation of airflow for at least 10 seconds whereas hypopnea as abnormal respiratory event with at least a $30 \%$ reduction in thoracoabdominal movement or airflow as compared to baseline lasting at least 10 seconds and with $>4 \%$ oxygen desaturation or an electroencephalographic arousal. Subjects with polysomnographic evidence of $\mathrm{AHI} \geq 5$ per hour were considered to be cases whereas subjects with AHI $<5$ per hour as controls. Sleep period time is the time in minutes from sleep onset to the final awakening. Total 
sleep time (TST) is time in minutes from sleep onset until the final awakening, less wake after sleep onset (WASO). Sleep onset is time in minutes after lights out when the first 30-sec epoch of any stage of sleep is observed. Sleep latency is the time in minutes from lights out to sleep onset. Rapid Eye Movement (REM) sleep latency is elapsed time in minutes from sleep onset, to, but not including, the first score-able epoch of REM sleep. Sleep stage percentages are percentages of total sleep time in each particular stage of sleep (Stages S1, S2, S3, S4, REM), determined by dividing recording time in each stage by TST. Arousal indexes are mean number of arousals per hour of sleep calculated by total number of arousals multiplied by 60 and divided by the total sleep time (N x 60/TST). The protocol of the study has been shown in Figure 1. The ethical committee of KGMU approved this present study.

\section{Statistical analysis}

All statistical analyses were performed using SPSS statistical software 16.0 (SPSS Inc., USA). Descriptive statistics of all continuous variables were calculated as means and standard deviation, whereas categorical data were expressed as percentages. A comparison between groups was done using Student's $t$-test for continuous variables, and chi-square test or Fisher's exact test was used for discrete variables. Rate differences between variables were calculated by odd ratios (ORs) and the corresponding 95\% confidence intervals (CIs). Variables showing association with a p-value of $<0.05$ in univariate analysis were considered as candidate risk factors to be used in multivariate analysis. Stepwise multiple logistic regression analysis was used to identify significant independent risk factors of OSAS. All tests were two-sided and a $p<0.05$ was considered statistically significant.

\section{Results}

In our study, 1512 apparently healthy adult subjects above the age group of 25 years underwent screening with $\mathrm{BQ}$. The demographic profile of 1512 subjects has been illustrated in Table 1. The mean body
Table 1. Demographic profile of the study population $(n=1512)$.

\begin{tabular}{ll} 
Variables & Values (\%) \\
Age (years) & \\
$25-34$ & $197(13.1 \%)$ \\
$35-44$ & $477(31.5 \%)$ \\
$45-54$ & $476(31.4 \%)$ \\
$55-64$ & $308(20.4 \%)$ \\
$\geq 65$ & $54(3.6 \%)$ \\
\hline Sex & \\
Male & $1028(67.9 \%)$ \\
Female & $484(32.1 \%)$ \\
\hline Habitat & \\
Urban & $1047(69.3 \%)$ \\
Rural & $465(30.7 \%)$ \\
\hline Body Mass index & \\
$\leq 24.9$ (healthy \& underweight) & $942(62.3 \%)$ \\
$25-29.9$ (overweight) & $385(25.5 \%)$ \\
$\geq 30$ (obese) & $185(12.2 \%)$ \\
\hline Neck size ( $\geq 17$ inch in male or $\geq 15$ inch in female) & \\
Yes & $73(4.8 \%)$ \\
No & $1439(95.2 \%)$ \\
\hline Excessive Daytime Sleepiness Score & \\
$\geq 11$ & $78(5.2 \%)$ \\
$<11$ & $1434(94.8 \%)$ \\
\hline Snoring & \\
Yes & $530(35.1 \%)$ \\
No & $982(64.9 \%)$ \\
\hline Hypertension & $133(8.8 \%)$ \\
Yes & $1379(91.2 \%)$ \\
\hline No & $1719(27.7 \%)$ \\
\hline Smoking & $1093(72.3 \%)$ \\
\hline Nes & $1333(11.8 \%)$ \\
\hline Alcoholism & \\
Yes & \\
No & \\
\hline Sedative or tranquillizers use & \\
Yes & \\
No & \\
\hline
\end{tabular}

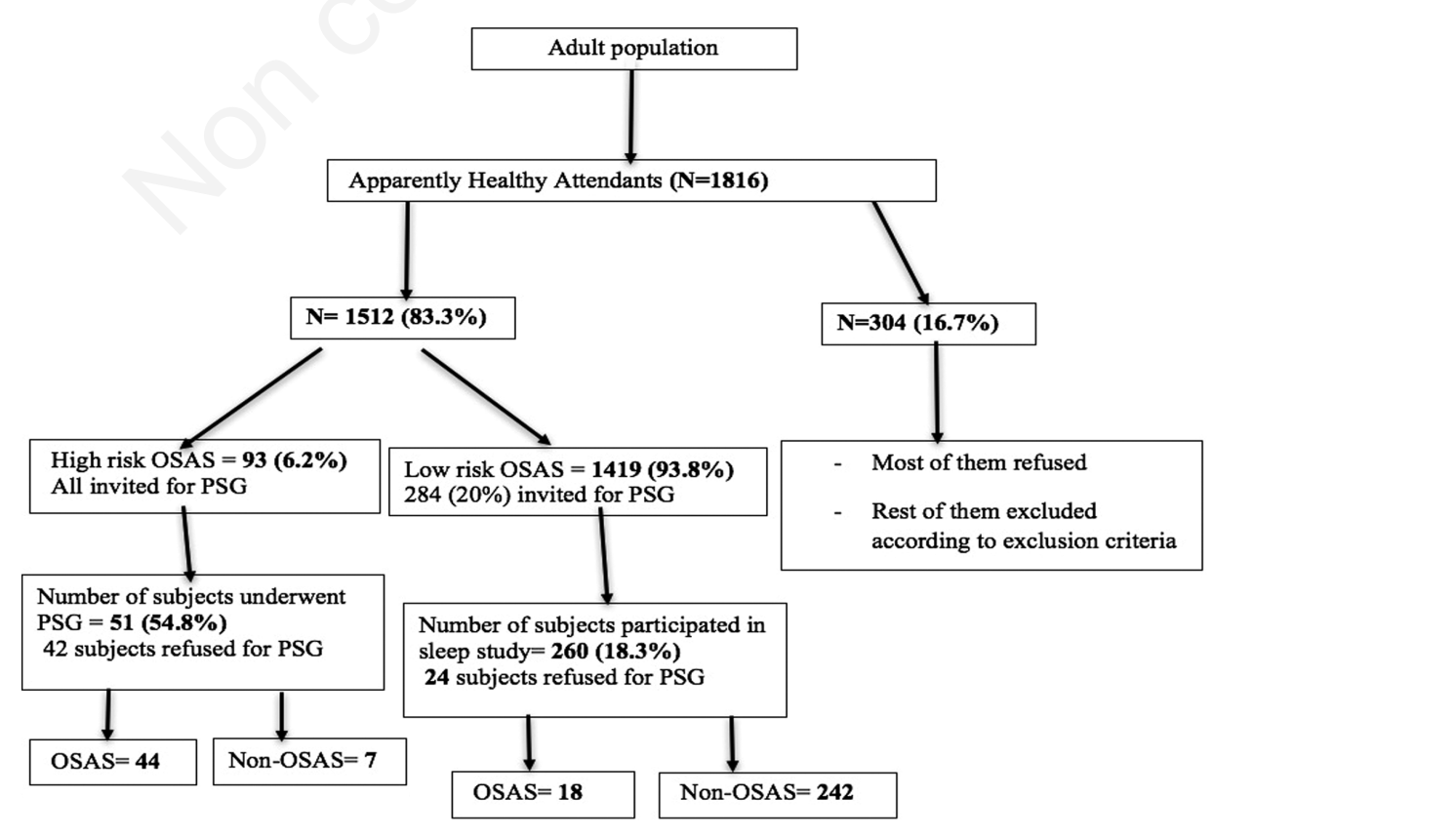

Figure 1. Protocol of the study. 
mass index, neck size and ESS score were higher in those patients who were at high risk of OSAS than the general adult population [30.8 \pm 5.2 vs $25.1 \pm 4.4,(\mathrm{p}<0.05) ; 15.9 \pm 1.9$ vs $14.2 \pm 1.6,(\mathrm{p}=0.10) ; 13.5 \pm 6.0$ vs $5.3 \pm 3.4$, $(\mathrm{p}<0.001)]$. Risk categorization for OSAS on the basis of responses to questionnaire has been illustrated in Table 2. Prevalence of high-risk OSAS was 70 (6.8\%) among total 1028 males whereas for 484 females, prevalence was 23 (4.8\%) with an overall prevalence of highrisk OSAS was 93 (6.2\%). Prevalence of high-risk OSAS was higher in males than females with statistically no significant difference; ( $\mathrm{p}=0.35$ ) 406/1028 (39.5\%), males vs 124/484 (25.6\%) females were snorers $(\mathrm{p}=0.003)$.

Out of 1512 subjects, 530 (35.1\%) were snorers and $982(64.9 \%)$ were non-snorers of which 357 (36.4\%) did not know whether they snore. Among 530 snorers, 312 (58.9\%) were loud snorers (i.e., more than talking) and 218 (41.1\%) were non-loud snorers (i.e., not more than talking); 335 (63.2\%) did snore frequently with ( $\geq 3-4)$ times per week or more and $195(36.8 \%)$ snored less frequently $(\leq 1-2)$ times per week; 231 (43.6\%) were bothersome snorers and 299(56.4\%) were non-bothersome snorers. And 48 (9.1\%) subjects reported frequent breathing pauses ( $\geq 3-4$ times/week or more), while 482 (90.9\%) subjects reported less frequent breathing pauses including those who had experienced never or almost never breathing pauses. One hundred and thirtyone $(8.7 \%)$ had reported morning tiredness $\geq 3-4$ times/week or more, while $1381(91.3 \%)$ reported less morning tiredness $\leq 1-2$ times/week or less, including those who had experienced never or almost never morning tiredness. One hundred and seventeen (7.7\%) had reported wake time tiredness $\geq 3-4$ times/week or more, while $1395(92.3 \%)$ reported less wake time tiredness $\leq 1-2$ times/week or less including those who had experienced never or almost never wake time tiredness. Seven hundred and twenty-six (48.1\%) were non-drivers as they did not know to drive or need not to drive (mainly villagers and females) and 786 (51.9\%) used to drive vehicles. Among 786 subjects, 52 (6.6\%) reported drowsiness while driving $\geq 3-4$ times/week or more while 734 (93.4\%) reported drowsiness $\leq 1-2$ times/ week or less including those who had never or almost never experienced drowsiness while driving. Seventy-eight (5.2\%) subjects were having excessive daytime sleepiness (ESS score $\geq 11$ ) and the remaining 1434 (94.8\%) were not having EDS (ESS score $<11)(\mathrm{p}<0.001)$. Prevalence of excessive daytime sleepiness (ESS score $\geq 11$ ) was $49(52.7 \%)$ among high-risk and 26 (1.8\%) low-risk OSAS subjects respectively $(\mathrm{p}<0.001)$. Prevalence of obesity was $185(12.2 \%)$ with $62 / 185(33.5 \%)$ were at a high risk for OSAS. One hundred and thirty-three (8.8\%) subjects were hypertensive with 58/133 (62.4\%) of them were at high risk of OSAS. Out of 1512 subjects, 40 (2.6\%) with $31(2.1 \%)$ males and $9(0.5 \%)$ females were having a clinically significant form of OSAS defined as obesity and snored at least 3-4 times per week and had associated EDS (ESS score $\geq 11$ ). Evaluation of risk Factors for OSAS in the adult population has been illustrated in Table 3. Obesity, neck size, alcoholism and sedatives/tranquillisers use were risk factors associated with statistical significance for high-risk OSAS and all were considered to be independent risk factors for OSAS when analysed further with a multivariate model. Fifty-one (54.8\%) high-risk OSAS and 260 (18.3\%) low-risk OSAS subjects finally participated for PSG (total number 311). Polysomnographic parameters such as ESS Score, AHI/hour, total oxygen desaturation, snore time, Stage 1 sleep (S1), Stage 2 sleep (S2), Arousal Index were statistically significant for OSAS (62) as compared to the non-OSAS cases (249) as mentioned in Table 4. The distribution of upper airway abnormalities among OSAS and non-OSAS cases are shown in Table 5. Mallampatti Grade III and IV are more commonly observed in OSAS cases as compared to non-OSAS cases where Mallampatti Grade I and II are observed more frequently. High-risk category predicted an AHI $\geq 5 /$ hr with sensitivity $86.3 \%$, specificity $93.1 \%$, positive and negative predictive values of $70.9 \%$ and $97.2 \%$, respectively. AHI distribution in various risk groups has also been illustrated in Table 6 . The diagnostic capability of $B Q$ at various levels of cut off for AHI ( $\geq 5 / \mathrm{hr}, \geq 15 / \mathrm{hr}$, $\geq 30 / \mathrm{hr}$ ) has been described in Table 7 .

\section{Discussion}

The public health impact of OSAS is enormous, particularly given some studies suggesting increased prevalence of OSAS in India compared to other countries and its potential contribution to the increased rates of cardiovascular disease noted in India, especially as life expectancy continues to increase. Its impact in developing countries like India is now being appreciated, as awareness regarding this entity was low among the general public as well as physicians previously. Our study was conducted on 1512 apparently healthy adults that were administered BQ for screening high risk for OSAS. The reason for taking cut off age limit as 25 years in the current study was that OSAS is more common in middle-aged subjects. The population above 65 years of age constitute only $3.5 \%$ of our study population as the chances of central sleep apnea are high in such age group rather than OSA and also a frequent association with various co-morbid illnesses which may give the false high prevalence of OSAS. We have used original version of $B Q$ to find out prevalence of high-risk OSAS, which was first used by Netzer et al. [7]. In our study, the prevalence of high risk and clinically significant OSAS were $6.2 \%$ (males- $4.6 \%$ and females- $1.5 \%$ ) and $2.6 \%$ (males- $2.1 \%$ and females-0.5\%) respectively. The prevalence of highrisk OSAS estimated worldwide was $4.6 \%-27.3 \%$ on the basis of studies using BQ without assessment of PSG whereas the prevalence of OSAS based on studies using BQ with assessment of PSG estimated to be $1.7 \%-12.2 \%$ [1,2,4-6,11-20]. Estimates of the prevalence of OSAS worldwide and even within different regions of India provide widely different figures probably because of differences in definitions, in the design of the studies and the investigations performed and in the age, sex and other characteristics of the population surveyed. Young et al. also reported $4 \%$ of men and $2 \%$ had sleep apnea syndrome in their study [1]. However, Netzer NC et al. reported the prevalence of OSAS in the adult population was $37.5 \%$, in $44.5 \%$ males and $33 \%$ females, which was much higher due to more obese population and more positive way of responding to questionnaire in their study [7]. The major drawback is that sleep questionnaires despite being useful in assessing risk for OSAS, are not interchangeable with instrumental sleep studies and cannot quantify the severity of the disease. Therefore, the prevalence of people at high risk for OSAS based on questionnaires cannot be simply converted into the prevalence of OSAS. In our study of adults in the age group 25 - 65 years, $35.1 \%$ were snorers, $63.6 \%$ were non-snorers and $36.4 \%$ did not know whether they snore. The prevalence of snoring estimated among various studies was 4.6\%-59.1\% [1,2,4-6,11-22]. Netzer et al. reported that $52.2 \%$ subjects were snorers, $30 \%$ nonsnorers and $15.9 \%$ did not know whether they snore [7]. 43.9\% males and $38.5 \%$ females were snorers in this current study. Lugaresi et al. also reported that $40 \%$ men and $28 \%$ of women were snorers [21]. The prevalence of high-risk OSAS, in adult obese population, was $33.5 \%$ significantly more than non-obese population $(\mathrm{p}<0.001)$ when the cutoff point for obesity was taken as BMI $\geq 30 \mathrm{~kg} / \mathrm{m}^{2}$ according to western population. However, when cut off value was taken as BMI $\geq 25 \mathrm{~kg} / \mathrm{m}^{2}$ for Asian population prevalence was found to be $18.8 \%$ [23]. These observations suggest that a significant percentage of our non-obese subjects by Western or Asian standards still had high-risk OSAS leading to postulate that other risk factors for OSAS such as upper airway abnormalities assume greater pathogenic significance in Indian subjects and may be responsible for our higher prevalence. Various studies in India 
Table 2. Risk categorization for OSAS on the basis of responses to Berlin Questionnaire.

\begin{tabular}{|c|c|c|c|c|}
\hline Berlin Questionnaire & $\begin{array}{l}\text { High-risk OSAS } \\
\text { Number (\%) }\end{array}$ & $\begin{array}{l}\text { Low-risk OSAS } \\
\text { Number }(\%)\end{array}$ & Total & p-value \\
\hline \multicolumn{5}{|l|}{ Category 1} \\
\hline $\begin{array}{l}\text { Do you snore? } \\
\text { Yes } \\
\text { No } \\
\text { Do not know }\end{array}$ & $\begin{array}{l}\mathbf{8 7}(\mathbf{9 3 . 5} \%) \\
4(4.3 \%) \\
2(2.2 \%)\end{array}$ & $\begin{array}{l}443(\mathbf{3 1 . 1} \%) \\
621(43.8 \%) \\
355(25.1 \%)\end{array}$ & $\begin{array}{l}\mathbf{5 3 0}(\mathbf{3 5 . 1} \%) \\
625(41.3 \%) \\
357(23.6 \%)\end{array}$ & $\mathrm{p}=0.18$ \\
\hline Total & 93 & 1419 & 1512 & \\
\hline $\begin{array}{l}\text { Snoring Loudness } \\
\text { Loud as breathing } \\
\text { Loud as talking } \\
\text { Louder than talking } \\
\text { Very loud }\end{array}$ & $\begin{array}{l}3(3.4 \%) \\
8(9.2 \%) \\
\mathbf{3 5}(\mathbf{4 0 . 2} \%) \\
\mathbf{4 1}(\mathbf{4 7 . 2 \% )}\end{array}$ & $\begin{array}{l}91(20.5 \%) \\
116(26.2 \%) \\
\mathbf{1 4 5}(\mathbf{3 2 . 7 \% )} \\
\mathbf{9 1 ( 2 0 . 6 \% )}\end{array}$ & $\begin{array}{l}94(17.8 \%) \\
124(23.4 \%) \\
\mathbf{1 8 0}(\mathbf{3 3 . 9 \% )} \\
\mathbf{1 3 2}(\mathbf{2 4 . 9 \% )}\end{array}$ & $\mathrm{p}<0.001$ \\
\hline Total & 87 & 443 & 530 & \\
\hline $\begin{array}{l}\text { Snoring Frequency } \\
\text { Almost everyday } \\
\mathbf{3 - 4} \text { times/week } \\
1-2 \text { times/week } \\
\text { 1-2 times/month } \\
\text { Never or almost never }\end{array}$ & $\begin{array}{l}\mathbf{7 2}(\mathbf{8 2 . 8 \% )} \\
\mathbf{8}(\mathbf{9 . 2 \% )} \\
3(3.4 \%) \\
2(2.3 \%) \\
2(2.3 \%)\end{array}$ & $\begin{array}{l}\mathbf{1 7 2}(\mathbf{3 8 . 8 \%}) \\
\mathbf{8 3}(\mathbf{1 8 . 7 \% )} \\
108(24.5 \%) \\
64(14.4 \%) \\
16(3.6 \%)\end{array}$ & $\begin{array}{l}244(\mathbf{4 6 . 1 \% )} \\
\mathbf{9 1}(\mathbf{1 7 . 2 \% )} \\
111(20.9 \%) \\
66(12.4 \%) \\
18(3.4 \%)\end{array}$ & $\mathrm{p}<0.001$ \\
\hline Total & 87 & 443 & 530 & \\
\hline $\begin{array}{l}\text { Does your snoring bother other people } \\
\text { Yes } \\
\text { No } \\
\text { Total }\end{array}$ & $\begin{array}{l}\mathbf{7 4}(\mathbf{8 5 . 1} \%) \\
13(14.9 \%) \\
\mathbf{8 7}\end{array}$ & $\begin{array}{l}\mathbf{1 5 7}(\mathbf{3 5 . 4 \% )} \\
286(64.6 \%) \\
\mathbf{4 4 3}\end{array}$ & $\begin{array}{l}\mathbf{2 3 1}(\mathbf{4 3 . 6 \% )} \\
299(56.4 \%) \\
\mathbf{5 3 0}\end{array}$ & $\mathrm{p}<0.001$ \\
\hline $\begin{array}{l}\text { How often your breathing pauses been noticed } \\
\text { Almost every day } \\
\text { 3-4 times/week } \\
\text { 1-2 times/week } \\
\text { 1-2 times/month } \\
\text { Never or almost never }\end{array}$ & $\begin{array}{l}26 \mathbf{( 2 9 . 9 \% )} \\
\mathbf{1 3}(\mathbf{1 4 . 9 \% )} \\
10(11.5 \%) \\
11(12.6 \%) \\
27(31.1 \%)\end{array}$ & $\begin{array}{l}\mathbf{2}(\mathbf{0 . 4 \% )} \\
\mathbf{7}(\mathbf{1 . 6 \% )} \\
2(0.4 \%) \\
63(14.3 \%) \\
369(83.3 \%)\end{array}$ & $\begin{array}{l}\mathbf{2 8}(\mathbf{5 . 3} \%) \\
\mathbf{2 0}(\mathbf{3 . 8} \%) \\
12(2.3 \%) \\
74(13.9 \%) \\
396(74.7 \%)\end{array}$ & $\mathrm{p}<0.001$ \\
\hline Total & 87 & 443 & 530 & \\
\hline Category 2 & 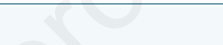 & & & \\
\hline $\begin{array}{l}\text { Are you tired after sleeping? } \\
\text { Almost every day } \\
\mathbf{3 - 4} \text { times/week } \\
\text { 1-2 times/week } \\
\text { 1-2 times/month } \\
\text { Never or almost never }\end{array}$ & $\begin{array}{l}\mathbf{5 0}(\mathbf{5 3 . 8 \% )} \\
\mathbf{1 9}(\mathbf{2 0 . 4 \% )} \\
5(5.4 \%) \\
6(6.5 \%) \\
13(13.9 \%)\end{array}$ & $\begin{array}{l}\mathbf{2 7}(\mathbf{1 . 9 \% )} \\
\mathbf{3 5}(\mathbf{2 . 4 \% )} \\
76(5.4 \%) \\
257(18.1 \%) \\
1024(72.2 \%)\end{array}$ & $\begin{array}{l}\mathbf{7 7}(\mathbf{5 . 1} \%) \\
\mathbf{5 4}(\mathbf{3 . 6 \%}) \\
81(5.4 \%) \\
263(17.3 \%) \\
1037(68.6 \%)\end{array}$ & $\mathrm{p}<0.001$ \\
\hline Total & 93 & 1419 & 1512 & \\
\hline $\begin{array}{l}\text { Are you tired during wake time? } \\
\text { Almost every day } \\
\mathbf{3 - 4} \text { times/week } \\
\text { 1-2 times/week } \\
\text { 1-2 times/month } \\
\text { Never or almost never }\end{array}$ & $\begin{array}{l}\mathbf{5 4}(\mathbf{5 8 . 1 \% )} \\
\mathbf{1 5}(\mathbf{1 6 . 1 \% )} \\
4(4.3 \%) \\
7(7.6 \%) \\
13(13.9 \%)\end{array}$ & $\begin{array}{l}24(\mathbf{1 . 7 \% )} \\
24(\mathbf{1 . 7 \%}) \\
113(7.9 \%) \\
170(11.9 \%) \\
1088(76.8 \%)\end{array}$ & $\begin{array}{l}\mathbf{7 8}(\mathbf{5 . 2 \% )} \\
\mathbf{3 9}(\mathbf{2 . 6 \% )} \\
117(7.7 \%) \\
177(11.7 \%) \\
1101(72.8 \%)\end{array}$ & $\mathrm{p}<0.001$ \\
\hline Total & 93 & 1419 & 1512 & \\
\hline $\begin{array}{l}\text { Are you driving? } \\
\text { Yes } \\
\text { No }\end{array}$ & & & $\begin{array}{l}786(51.9 \%) \\
726(48.1 \%)\end{array}$ & \\
\hline $\begin{array}{l}\text { How often you ever nodded off or fallen asleep while driving? } \\
\text { Almost every day } \\
\mathbf{3 - 4} \text { times/week } \\
\text { 1-2 times/week } \\
\text { 1-2 times/month } \\
\text { Never or almost never }\end{array}$ & $\begin{array}{l}\mathbf{2 8}(\mathbf{3 0 . 1} \%) \\
\mathbf{1 6}(\mathbf{1 7 . 2 \% )} \\
3(3.2 \%) \\
11(11.8 \%) \\
35(37.7 \%)\end{array}$ & $\begin{array}{l}\mathbf{3}(\mathbf{0 . 4 \% )} \\
\mathbf{5}(\mathbf{0 . 7 \% )} \\
8(1.2 \%) \\
74(10.6 \%) \\
603(87.1 \%)\end{array}$ & $\begin{array}{l}31(3.9 \%) \\
21(2.7 \%) \\
11(1.4 \%) \\
85(10.8 \%) \\
638(81.2 \%)\end{array}$ & $\mathrm{p}<0.001$ \\
\hline Total & 93 & 693 & 786 & \\
\hline \multicolumn{5}{|l|}{ Category 3} \\
\hline $\begin{array}{l}\text { Whether hypertensive on Examination? } \\
\text { Yes } \\
\text { No }\end{array}$ & $\begin{array}{l}\mathbf{5 8}(\mathbf{6 2 . 4 \% )} \\
35(37.6 \%)\end{array}$ & $\begin{array}{l}\mathbf{7 5} \mathbf{( 5 . 3 \% )} \\
1344(94.7 \%)\end{array}$ & $\begin{array}{l}133(\mathbf{8 . 8 \%}) \\
1379(91.2 \%)\end{array}$ & $\mathrm{p}<0.001$ \\
\hline Total & 93 & 1419 & 1512 & \\
\hline $\begin{array}{l}\text { Has your weight changed? Whether BMI is } \geq 30 \mathrm{~kg} / \mathrm{m}^{2} \text { ? } \\
\text { Yes } \\
\text { No }\end{array}$ & $\begin{array}{l}\mathbf{6 2}(\mathbf{6 6 . 7 \%}) \\
31(33.3 \%)\end{array}$ & $\begin{array}{l}123(\mathbf{8 . 7 \% )} \\
1296(91.3 \%)\end{array}$ & $\begin{array}{l}185(\mathbf{1 2 . 2 \%}) \\
1327(87.8 \%)\end{array}$ & $\mathrm{p}<0.001$ \\
\hline Total & 93 & 1419 & 1512 & \\
\hline
\end{tabular}


Table 3. Evaluation of risk factors for OsaS in adult population.

\begin{tabular}{|c|c|c|c|c|c|c|c|c|}
\hline Risk factors & $\begin{array}{l}\text { Categories } \\
\text { of risk } \\
\text { factors }\end{array}$ & $\begin{array}{l}\text { High risk } \\
\text { OSAS } \\
\text { No. (\%) }\end{array}$ & $\begin{array}{l}\text { Low risk } \\
\text { OSAS } \\
\text { No. (\%) }\end{array}$ & $\begin{array}{l}\text { Total } \\
\text { No. (\%) }\end{array}$ & $\begin{array}{l}\text { Unadjusted } \\
\text { Odds Ratio } \\
(95 \% \mathrm{CI})\end{array}$ & p-value & $\begin{array}{l}\text { Adjusted } \\
\text { Odds Ratio } \\
(95 \% \text { CI) }\end{array}$ & p-value \\
\hline $\begin{array}{l}\text { Obesity } \\
\left(\text { BMI } \geq 30 \mathrm{Kg} / \mathrm{m}^{2}\right)\end{array}$ & $\begin{array}{l}\text { Present } \\
\text { Absent }\end{array}$ & $\begin{array}{l}62(66.7 \%) \\
31(33.3 \%)\end{array}$ & $\begin{array}{l}123(8.7 \%) \\
1296(91.3 \%)\end{array}$ & $\begin{array}{l}185(12.2 \%) \\
1327(87.8 \%)\end{array}$ & $26.15(14.84-47.38)$ & $\mathrm{p}<0.001$ & $22.31(12.84-43.20)$ & $\mathrm{p}<0.001$ \\
\hline $\begin{array}{l}\text { Neck size ( } \geq 17 \text { " in male } \\
\text { or } \geq 15 \text { " in female) }\end{array}$ & $\begin{array}{l}\text { Present } \\
\text { Absent }\end{array}$ & $\begin{array}{l}29(31.2 \%) \\
64(68.8 \%)\end{array}$ & $\begin{array}{l}44(3.1 \%) \\
1375(96.9 \%)\end{array}$ & $\begin{array}{l}73(4.8 \%) \\
1439(95.2 \%)\end{array}$ & $8.52(4.51-16.08)$ & $\mathrm{p}<0.001$ & $6.72(2.25-13.63)$ & $\mathrm{p}<0.001$ \\
\hline Male sex & $\begin{array}{l}\text { Present } \\
\text { Absent }\end{array}$ & $\begin{array}{l}70(75.3 \%) \\
23(24.7 \%)\end{array}$ & $\begin{array}{l}958(67.5 \%) \\
461(32.5 \%)\end{array}$ & $\begin{array}{l}1028(67.9 \%) \\
484(32.1 \%)\end{array}$ & $1.32(0.74-2.37)$ & $\mathrm{p}=0.42$ & & \\
\hline Smoking & $\begin{array}{l}\text { Present } \\
\text { Absent }\end{array}$ & $\begin{array}{l}30(32.3 \%) \\
63(67.7 \%)\end{array}$ & $\begin{array}{l}389(27.4 \%) \\
1030(72.6 \%)\end{array}$ & $\begin{array}{l}419(27.7 \%) \\
1093(72.3 \%)\end{array}$ & $1.32(0.75-2.34)$ & $\mathrm{p}=0.40$ & & \\
\hline Alcoholism & $\begin{array}{l}\text { Present } \\
\text { Absent }\end{array}$ & $\begin{array}{l}27(29.1 \%) \\
66(70.9 \%)\end{array}$ & $\begin{array}{l}152(10.7 \%) \\
1267(89.3 \%)\end{array}$ & $\begin{array}{l}179(11.8 \%) \\
1333(88.2 \%)\end{array}$ & $2.56(1.46-4.49)$ & $\mathrm{p}<0.001$ & $2.02(1.51-3.83)$ & $\mathrm{p}<0.01$ \\
\hline $\begin{array}{l}\text { Sedative or } \\
\text { tranquiliser use }\end{array}$ & $\begin{array}{l}\text { Present } \\
\text { Absent }\end{array}$ & $\begin{array}{l}15(16.1 \%) \\
78(83.9 \%)\end{array}$ & $\begin{array}{l}50(3.5 \%) \\
1369(96.5 \%) \\
\end{array}$ & $\begin{array}{l}65(4.3 \%) \\
1447(95.7 \%) \\
\end{array}$ & $4.41(2.17-8.99)$ & $\mathrm{p}<0.001$ & $3.69(2.15-6.55)$ & $\mathrm{p}<0.001$ \\
\hline
\end{tabular}

Table 4. Comparison of polysomnography parameters in the OSAS and non-OSAS groups.

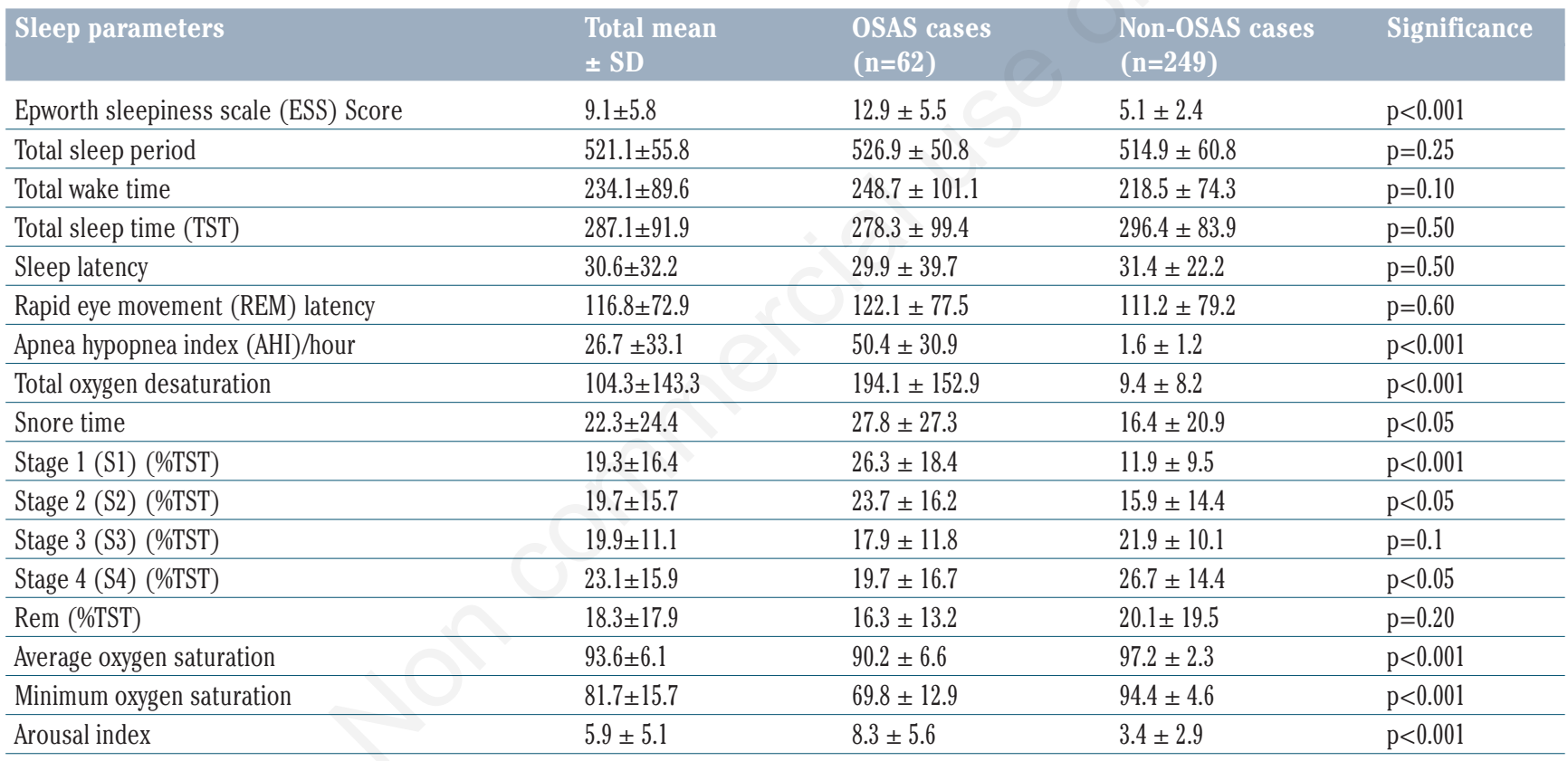

Table 5. Upper respiratory tract (URT) abnormalities in OSAS $(n=62)$ and non-OSAS cases $(n=249)$.

\begin{tabular}{|c|c|c|c|}
\hline URT abnormalities & $\begin{array}{l}\text { OSAS cases } \\
(n=62)\end{array}$ & $\begin{array}{l}\text { Non-OSAS } \\
\text { cases }(n=249)\end{array}$ & $\begin{array}{l}\text { Total } \\
(n=311)\end{array}$ \\
\hline Macroglossia & $17(27.4 \%)$ & $3(1.2 \%)$ & $20(6.4 \%)$ \\
\hline Pharyngeal crowding & $26(41.9 \%)$ & $11(4.4 \%)$ & $37(11.9 \%)$ \\
\hline Bulky uvula & $20(32.3 \%)$ & $9(3.6 \%)$ & $29(9.3 \%)$ \\
\hline Retrognathia & $33(53.2 \%)$ & $18(7.2 \%)$ & $51(16.4 \%)$ \\
\hline Tonsillar enlargement & $8(12.9 \%)$ & $3(1.2 \%)$ & $11(3.5 \%)$ \\
\hline Deviated nasal septum & $35(56.5 \%)$ & $21(8.4 \%)$ & $56(18.1 \%)$ \\
\hline Mallampatti Grade I & $6(9.7 \%)$ & $112(44.9 \%)$ & $118(37.9 \%)$ \\
\hline Mallampatti Grade II & $16(25.8 \%)$ & $93(37.3 \%)$ & $109(35.1 \%)$ \\
\hline Mallampatti Grade III & $22(35.5 \%)$ & $44(17.7 \%)$ & $66(21.2 \%)$ \\
\hline Mallampatti Grade IV & $14(22.3 \%)$ & $4(1.6 \%)$ & $18(5.8 \%)$ \\
\hline
\end{tabular}


Table 6. Apnea hypopnea index (AHI) distribution in various risk groups for OSAS.

\begin{tabular}{llll}
\hline AHI/hr (Grading) & High risk OSAS & Low risk OSAS & Total \\
$<5$ & $7(13.7 \%)$ & $242(93.1 \%)$ & $249(80.1 \%)$ \\
\hline$\geq 5$ and $<15$ (Mild) & $6(11.8 \%)$ & $11(4.3 \%)$ & $17(5.5 \%)$ \\
\hline$\geq 15$ and $\leq 30$ (Moderate) & $14(27.5 \%)$ & $6(2.3 \%)$ & $20(6.4 \%)$ \\
\hline$>30$ (Severe) & $24(47.1 \%)$ & $1(0.1 \%)$ & $25(8.1 \%)$ \\
\hline Total & $\mathbf{5 1}$ & $\mathbf{2 6 0}$ & $\mathbf{3 1 1}$ \\
\hline
\end{tabular}

Table 7. Diagnostic capability of BQ at various levels of cut off for AHI ( $\geq 5 / \mathrm{hr}, \geq 15 / \mathrm{hr}, \geq 30 / \mathrm{hr})$.

\begin{tabular}{llll} 
& $\begin{array}{l}\text { AHI } \geq 5 \\
(95 \% \text { Confidence Interval) }\end{array}$ & $\begin{array}{l}\text { AHI } \geq 15 \\
(95 \% \text { Confidence Interval) }\end{array}$ & $\begin{array}{l}\text { AHI } \geq 30 \\
(95 \% \text { Confidence Interval) }\end{array}$ \\
\hline Sensitivity & $86.3 \%(73.1-93.8)$ & $78.7 \%(66.1-87.8)$ & $47.1 \%(33.2-61.4)$ \\
\hline Specificity & $93.1 \%(89.1-95.7)$ & $97.7 \%(94.8-99.1)$ & $99.6 \%(97.5-99.9)$ \\
\hline Positive predictive value & $70.9 \%(57.9-81.4)$ & $88.9 \%(76.7-95.4)$ & $96.0 \%(77.7-99.8)$ \\
\hline Negative predictive value & $97.2 \%(94.1-98.8)$ & $95.1 \%(91.6-97.3)$ & $90.6 \%(86.4-93.6)$ \\
\hline Positive likelihood ratio & $12.5(7.9-19.7)$ & $18.0(9.8-20.1)$ & $24.2(8.6-27.2)$ \\
\hline Negative likelihood ratio & $0.2(0.1-0.3)$ & $0.1(0.0-0.2)$ & $0.1(0.0-0.2)$ \\
\hline Odds ratio & $4.5(1.3-14.2)$ & $6.4(2.2-17.5)$ & $7.9(2.6-23.5)$ \\
\hline Area under curve & $0.9(0.8-0.9)$ & $0.8(0.7-0.9)$ & $0.8(0.7-0.9)$ \\
\hline
\end{tabular}

have used BMI $\geq 25 \mathrm{~kg} / \mathrm{m}^{2}$ as a cut-off value for obesity providing similar inferences $[2,4,6,24]$. The prevalence of high-risk OSAS, in obese males as well as females were $48.4 \%$ and $43.3 \%$ respectively which was not significant ( $\mathrm{p}=0.6)$. Vgontzas et al. [5] reported that in a large group of severely or morbidly obese patients, $40 \%$ men and $3 \%$ of women demonstrated OSAS severe enough to warrant therapeutic intervention. In our study among adults, the prevalence of hypertension was $62.4 \%$ in highrisk OSAS patients and $5.3 \%$ in low-risk OSAS adult subjects. The prevalence of hypertension was significantly higher in high-risk OSAS patients than low-risk OSAS subjects. Various studies also found significant association between high-risk OSAS and hypertension [26-28]. In our study, the risk factors for OSAS with statistical significance were obesity $(\mathrm{p}<0.001)$, neck size (17 inches in male or 15 inch in female) $(\mathrm{p}<0.001)$; alcoholism $(\mathrm{p}<0.001)$ and sedatives/ tranquillizers use $(\mathrm{p}<0.001)$. Flemons WW et al also reported neck size even $16.1 \pm 1.4$ inch was significant risk factor for OSAS $(\mathrm{p}<0.001)$ [29]. Several studies have found a significant association between OSAS and measures of excess body weight [1,11,13,30-39]. Many studies in which defined quantities of alcohol were administered to healthy subjects or patients with OSAS before bedtime have demonstrated harmful effects on nocturnal respiration including increased number and duration of hypopnea and apnea events [40-45]. Many cross-sectional epidemiological studies of OSAS have found positive associations with cigarette smoking [4,4648]. Another analysis from Sleep Heart Health Studies also found an inverse association between current smoking and OSAS, after adjusting for several factors including age and BMI, current smokers had significantly fewer respiratory disturbance events as assessed by in-home polysomnography [49]. A high-risk group for OSAS was predicted with a sensitivity of $86.3 \%$, specificity of $93.1 \%$, positive predictive value of $70.9 \%$ and negative predictive value of $97.2 \%$. The predictive performance of the $\mathrm{BQ}$ varies among different populations studied worldwide. The original BQ study conducted by Netzer NC et al. depicted sensitivity $=88 \%$, specificity $=76 \%$, positive predictive value $=88 \%$ and negative predictive value $=81 \%$ [7]. The performance of the $\mathrm{BQ}$ in our population is comparable to that of studies conducted in other Indian population and Arabia with a sensitivity of $86 \%$ and specificity of $95 \%$, and a sensitivity of $97 \%$ and specificity of $90 \%$ respectively at a cut-off of AHI $\geq 5$ where a modified version of the $\mathrm{BQ}$ was used $[23,50]$. The results of our study differ from other studies in the literature, where the $\mathrm{BQ}$ was shown to have lower sensitivity and specificity (68\% and $49 \%$ for AHI $\geq 5$ ) in one study, sensitivity and specificity, $62.5 \%$ and $53.8 \%$ with a cutoff for $\mathrm{AHI} \geq 10$ in patients undergoing pulmonary rehabilitation, sensitivity and specificity of $72 \%$ and $50 \%$ for $\mathrm{AHI} \geq 5$ in a sleep laboratory in Portugal, in a hypertension clinic ( $86 \%$ and $65 \%$ for $\mathrm{AHI}>10$ ), in pre-operative patients ( $69 \%$ and $56 \%$ for $\mathrm{AHI} \geq 5)$ and in Greece ( $76 \%$ and $40 \%$ for $\mathrm{AHI} \geq 5$ ) [51-56]. The reasons for the difference in the predictive performance across the various studies might be related to several possible factors such as heterogeneity in demographic profiles of patients, the difference in methods for assessing patients at risk including modifications of the questionnaire and different types of sleep monitoring devices used. The developing countries like India are heavily populated with diverse social norms and many groups live in an underdeveloped environment. These factors can be considered as obstacles in assessing the disease burden by performing polysomnography which is labour intensive and time-consuming. Therefore, BQ can screen those subjects with symptoms of high-risk OSAS from this population and can undergo PSG on a priority basis for management as compared to subjects with low-risk OSAS.

Our study has several strengths. This study is the first to estimate the prevalence of OSAS in a semi-urban population from this region of India where majorities of the general public are more unaware of disease severity with less interest to undergo treatment in contrast to the population in urbanised metropolitan cities on which previous studies were conducted. There was still satisfactory response rate with robust sample size as conducted in resource-limited settings. The predictive performance of risk categorization by $\mathrm{BQ}$ was compared to gold standard supervised in-laboratory polysomnography in the current study. The apparently normal attendants accompanying patients reporting to a tertiary care referral centre from all parts of the state that were having no complaints were recruited in this study. The patients directly reporting with symptoms of OSAS were not included in order to avoid selection bias. 
This study has also several limitations. Most of the subjects are attendants of patients thereby not representing actual proportion of the community, therefore, the findings have to be generalised by conducting community-based surveys. Community studies are more likely to portray epidemiology with better accuracy than single-centre hospital studies. Second, the hospital studies usually recruit patients with a high pre-test probability of diagnosis, which is true for studies using questionnaires/ symptomatology as well as polysomnography studies. Third, the mean BMI of the population in this study was high that was likely to have affected the sensitivity and specificity of the $\mathrm{BQ}$, as the BMI contributes significantly into the scoring of the BQ. Fourth, a larger number of subjects could have been recruited for polysomnography especially from low-risk OSAS subjects as only the high-risk OSAS subjects who had sleep symptoms selectively consented to the overnight PSG. The proportion of females is less as compared to males (33\%). The practical reason for fewer females was bearing in mind Indian social norms as they would have been reluctant to allow a male technician to allow for overnight PSG and more lack of awareness regarding the severity of disease as compared to males. Most Indian females are non-drivers thereby leading to inappropriate risk categorization by $\mathrm{BQ}$.

The sensitivity of $86.3 \%$ (for an $\mathrm{AHI} \geq 5$ ) has made an impression regarding the $\mathrm{BQ}$ that it still can be used as a pre-assessment tool for predicting persons at risk for OSAS in clinical practice. The prediction value of $B Q$ can be enhanced by further modification according to the requirement of respective settings. However, physician judgment is still needed to initiate a management system, to detect unusual cases, or to recognise causes for wake time sleepiness other than sleep apnea. Further studies on applying the BQ in a larger sample of patients are warranted in near future from other regions of India.

\section{References}

1. Young TJ, Palta M, Dempsey J et. al. The occurrence of sleep-disordered breathing among middle-aged adults. N Eng J Med 1993; 328:1230-5.

2. Sharma SK, Kumpawat S, Banga A, Goel A. Prevalence and risk factors of obstructive sleep apnoea syndrome in a population of Delhi, India. Chest 2006;130:149-56.

3. Gibson GJ. Obstructive sleep apnoea syndrome: underestimated and undertreated. Br Med Bull 2005;72:49-65.

4. Reddy EV, Kadhivaran T, Mishra HK, et al. Prevalence and risk factors of obstructive sleep apnea among middle-aged urban Indians: A community-based study. Sleep Med 2009;10:913-8.

5. Vijayan VK, Patial K. Prevalence of obstructive sleep apnoea syndrome in Delhi, India. Chest 2006: 130: 92S.

6. Udwadia ZF, Doshi AV, Lonkar SG, Singh CI. Prevalence of sleep disordered breathing and sleep apnea in middle-aged urban Indian men. Am J Respir Crit Care Med 2004;169:168-73.

7. Netzer NC, Stoohs RA, Netzer CM, et. al. Using the Berlin Questionnaire to identify patients at risk for the sleep apnea syndrome. Annals internal Medicine 1999:131:485-91.

8. Johns MW. A new method for measuring daytime sleeping, the Epworth Sleepiness scale. Sleep 1991;14:540-45.

9. Chobanian AV, Bakris GL, Black HR, et. al. Seventh report of the Joint National Committee on prevention, detection, evaluation, and treatment of high blood pressure. Hypertension 2003;42: 1206-52.

10. World Health Organization. Obesity: preventing and managing the global epidemic of obesity. Report of the WHO Consultation of Obesity. 1997; Geneva, Switzerland.
11. Stradling JR, Crosby JH. Predictors and prevalence of obstructive sleep apnoea and snoring in 1001 middle-aged men. Thorax 1991; 46:85-90.

12. Jennum P, Sjol A. Epidemiology of snoring and obstructive sleep apnoea in a Danish Population, age 30-60. J Sleep Res. 1992;1:240-4.

13. Bearpark H, Elliott L, Grunstein R, et al. Occurrence and correlate of sleep disordered breathing in the Australian town of Busselton: A preliminary analysis. Sleep 1993;16:53-5.

14. Gislason T, Almquist M, Eriksson G, et. al. Prevalence of sleep apnoea syndrome among Swedish men: an epidemiological study. J Clin Epidemiol. 1988; 41: 571-76.

15. Cirignotta F, D’Alessandro R, Partinen M, et al. Prevalence of every night snoring and obstructive sleep apneas among 30-69-year-old men in Bologna, Italy. Acta Psychiatr Scand 1980;79: 66-72.

16. Olson L G, King MT, Hensley MJ, Saunders NA. A community study of snoring and sleep-disordered breathing: Prevalence. Am J Respir Crit Care Med1995;152:711-6.

17. Bixler EO, Vgontzas AN, Lin HM, et. al. Prevalence of sleep-disordered breathing in women: effects of gender. Am J Respir Crit Care Med 2001;163:608-13.

18. Duran J, Esnaola S, Rubio R, Iztueta A. Obstructive sleep apnoea and related clinical features in a population-based sample of subjects aged 30-70 years. Am J Respir Crit Care Med 2001;163:685-9.

19. Adewole 00, Hakeem A, Fola A, et al. Obstructive sleep apnoea among adults in Nigeria. J Natl Med Assoc 2009;101:720-5.

20. Mirrakhimov AE, Sooronbaev T, Mirrakhimov EM. Prevalence of obstructive sleep apnea in Asian adults: a systematic review of the literature. BMC Pulmonary Medicine 2013;13:10.

21. Lugraesi E, Coccagna G, Cirignatta F. Snoring and its clinical implications. In: Guillemault C, Dement WC (eds.), Sleep apnea syndromes. New York; AR Liss, 1978; pp. 13-21.

22. Gottlieb DJ, Whitney CW, Bonekat WH, et al. for the Sleep Heart Health Study Research Group. Relation of sleepiness to respiratory disturbance index: the Sleep Heart Health Study. Am J Respir Crit Med 1999;15: 502-7.

23. World Health Organization, Western Pacific Region. The AsiaPacific Perspective. Redefining obesity and its treatment. WHO/IASO/IOTF: Melbourne: International Diabetes Institute, 2000; pp. 15-21.

24. Sharma SK, Vasudev C, Sinha S, et.al. Validation of the modified Berlin questionnaire to identify patients at risk for the obstructive sleep apnoea syndrome. Indian J Med Res 2006; 24:281-90.

25. Vgontzas AN, Tan TL, Bixler E0, et al. Sleep apnea and sleep disruption in obese patients. Arch Intern Med 1994;154:1705-11.

26. Bixler EO, Vgontzas AN. Lin HM, et al. Association of hypertension and sleep-disordered breathing. Arch Intern Med 2000; 160: 2289-95.

27. Grote L, Hender J, Peter JH. Mean blood pressure, pulse pressure and grade of hypertension in untreated hypertensive patients with a sleep-related breathing disorder. J Hypertens 2001;19: 683-90.

28. Lavie P, Herer P, Hoffstien V. Obstructive sleep apnoea syndrome as a risk factor for hypertension: a population study. Br Med J 2000; $320: 479-82$.

29. Flemons WW. Whitelaw WA, Brant R, Remmers JE. Likelihood ratios for a sleep apnea clinical prediction rule. Am J Respir Crit Care Med 1994 150:1279-85.

30. Grunstein R. Wilcox I, Yang TS, et al. Snoring and sleep apnoea in men: association with central obesity and hypertension. Int J Obes Relat Metab Disord 1993;17:533-40.

31. Davies RJ, Stradling JR. The relationship between neck circumference, radiographic pharyngeal anatomy, and the obstructive sleep apnoea syndrome. Eur Respir J 1990;3:509-14. 
32. Davies RJ, Ali NJ, Stradling JR. Neck circumference and other clinical features in the diagnosis of the obstructive sleep apnoea syndrome Thorax 192;47:101-5.

33. Hoffstein V, Mateika S. Differences in abdominal and neck circumferences in patients with and without obstructive sleep apnoea. Eur Respir J 1992;5:377-81.

34. Katz I Stradling J, Slutsky AS, et. al. Do patients with obstructive sleep apnea have thick necks? Am Rev Respir Dis 1990:141: 1228-33.

35. Levinson PD, McGarvey ST, Carlisle CC, et al. Adiposity and cardiovascular risk factors in men with obstructive sleep apnea. Chest 1993;103:1336-42.

36. Millman RP, Carlisle CC, Mc Garvey ST, et al. Body fat distribution and sleep apnea severity in women Chest 1995;107:362-6.

37. Shelton KE, Woodson H, Gay S, Suratt PM. Pharyngeal fat in obstructive sleep apnoea. Am Rev Respir Dis 1993;148:462-6.

38. Shinohara E, Kihara S, Yamashita S, et al. Visceral fat accumulation as an important risk factor for obstructive sleep apnea syndrome in obese subjects. J Intern Med 1997;241:11-8.

39. Enright PL, Newman AB, Wahi PW, et al. Prevalence and correlates of snoring and observed apneas in 5,201 older adults. Sleep 1996; 19:531-8.

40. Dolly FR, Block AJ. Increased ventricular ectopy and sleep apnea following ethanol ingestion in COPD patients. Chest 1983;83:469-72.

41. Issa FG, Sullivan CE. Alcohol, snoring and sleep apnea. J Neurol Neurosurg 1982;45:353-9.

42. Mitler MM, Dawson A, Henriksen SJ, et. al. Bedtime ethanol increases resistance of upper airways and produces sleep apneas in asymptomatic snorers. Alcohol Clin Exp Res 1988;12:801-5.

43. Scanlan MF, Roebuck T, Little PJ, et al. Effect of moderate alcohol upon obstructive sleep apnoea. Eur Respir J 2000;16:913.

44. Tansan VC, Block AJ, Boysen PG, Wynne JW. Alcohol increases sleep apnea and oxygen desaturation in asymptomatic men. Am J Med 1981;71:240-5.

45. Tsutsumi W, Miyazaki S, Itasaka Y, Togawa K. Influence of alcohol on respiratory disturbance during sleep. Psychiatry Clin Neurosci 2000;54:332-3.
46. Jennum P. Hein HO, Suadicani P, Gyntelberg F. Cardiovascular factors in snorers: a cross-sectional study of 3,323 men aged 54-74 years. The Copenhagen Male Study. Chest 1992;102:1371-6.

47. Jennum P. Sjol A. Snoring, sleep apnoea and cardiovascular risk factors: the MONICA II Study Int J Epidemiol 1993;22:439-44.

48. Wetter DW, Young TB, Bidwell TR, et al. Smoking as a risk factor for sleep-disordered breathing. Arch Intern Med 1994; 154: 2219-24.

49. Newman AB, Nieto FJ, Guidry U, et al. Relation of sleep-disordered breathing to cardiovascular disease risk factors: The Sleep Heart Health Study: Am J Epidemiol 2001;154:50-9.

50. Saleh AB, Ahmad MA, Awadalla NJ. Development of Arabic version of Berlin questionnaire to identify obstructive sleep apnea at risk patients. Ann Thorac Med 2011; 6:212-6.

51. Chung F, Yegneswaran B, Liao P, et al. Validation of the Berlin questionnaire and American society of anesthesiologists' checklist as screening tools for obstructive sleep apnea in surgical patients. Anaesthesiology 2008;108:822-30.

52. Vaz AP, Drummond M, Mota PC, et al. Translation of Berlin questionnaire to Portuguese language and its application in OSA identification in a sleep disordered breathing clinic. Rev Port Pneumol 2011;17:59-65.

53. Gus M, Gonçalves SC, Martinez D, et al. Risk for obstructive sleep apnea by Berlin questionnaire, but not daytime sleepiness, is associated with resistant hypertension: a case-control study. Am J Hypertens 2008;21:832-3.

54. Ahmadi N, Chung SA, Gibbs A, Shapiro CM: The Berlin questionnaire for sleep apnea in a sleep clinic population: relationship to polysomnographic measurement of respiratory disturbance. Sleep Breath 2008;12:39-45.

55. Weinreich G, Plein K, Teschler T, Resler J. Is the Berlin questionnaire an appropriate diagnostic tool for sleep medicine in pneumological rehabilitation. Pneumologie 2006;60:737-42.

56. Bouloukaki I, Komninos ID, Mermigkis C, et al. Translation and validation of Berlin questionnaire in primary health care in Greece. BMC Pulmon Med 2013;13:6. 